\title{
Atlas of Regional Anesthesia 4th Edition
}

\author{
David L. Brown. Saunders Elsevier, 2010, 416 pages. ISBN 978-1-4160-6397-1
}

\author{
Alan Lane, MB
}

Published online: 3 December 2010

(C) Canadian Anesthesiologists' Society 2010

This book, now in its fourth edition, is a beautifully illustrated text that deals with the expanding subject of regional anesthesia. The 51 chapters in this text comprise all the blocks involving the upper and lower limbs, head and neck, airway, and truncal and neuraxial regions. The chronic pain section also covers relevant pain blocks and includes chapters on intrathecal catheters and spinal cord stimulators.

This latest edition expands on the role of ultrasoundguided techniques, and respected new authors have contributed their ultrasound experience to the chapters on upper and lower limb blocks. In addition, this book offers online access to 12 videos demonstrating the ultrasoundguided approach to the more commonly performed blocks. An additional new chapter in this edition is allotted to a review of the transverses abdominis plane block.

A great feature of this book is the use of wonderful highquality illustrations and images that facilitate easy understanding of the relevant anatomy required to perform blocks. The easy-to-read chapters detail each block technique and potential complications and include useful performance tips. The online access to videos is useful, as is the ability to download images. The videos for each block are short and without sound, but they are explained clearly within the text. In addition, there is a bibliography at the end, which is an excellent reference.

This atlas is a good resource for any anesthesia departmental library. For novice practitioners or anesthesia assistants, it provides clear descriptions and illustrations for a wide range of blocks and introduces the basic ultrasound techniques. I also like the fact that the book covers the relevant chronic pain blocks and techniques, topics with which residents must become familiar. Then again, this atlas may have limitations for the more advanced practitioner. Specifically, many of the block techniques described are based on a more traditional approach, and there is insufficient detail concerning optimizing needle position prior to injection. Despite these limitations, this atlas is easy to use and a great introduction to regional anesthesia.

A. Lane, MB ( $\varangle)$

The Ottawa Hospital, Ottawa, ON, Canada

e-mail: alane@ottawahospital.on.ca 